\title{
APLIKASI ABSENSI SISWA MENGGUNAKAN QR CODE DENGAN BAHASA PEMROGRAMAN PHP DI SMKIT ZUNURAIN AQILA ZAHRA DI PELINTUNG
}

\author{
Nur Rubiati ${ }^{1}$, Sahara Widya Harahap ${ }^{2}$ \\ ${ }^{1,2}$ Sekolah Tinggi Manajemen Informatika dan Komputer (STMIK) Dumai \\ Jalan Bukit Batrem Kota Dumai kode pos 28811 \\ e-mail : nurrubiati0412@gmail.com ${ }^{1}$
}

\begin{abstract}
ABSTRAK
SMK Zunurain Aqila Zahra merupakan suatu lembaga pendidikan tingkat menengah yang didirikan oleh Yayasan Aqila Zahra Dumai. Setiap kegiatan yang membutuhkan informasi mengenai peserta didik (siswa) akan memerlukan absensi. Proses absensi yang masih manual yaitu dengan menulis dibuku yang membutuhkan waktu lama dan sering terjadi kecurangan absensi. Dengan masalah tersebut maka dibuatlah sebuah aplikasi dengan menggunakan QR Code (Quick Response Code) dan berbasis Web. Metode yang digunakan dengan melalui beberapa tahapan seperti pengumpulan data, mengidentifikasi masalah, analisis sitem, perancangan system, pembangunan system,pengujian system, implementasi system. Aplikasi Web ini dibangun menggunakan 3 komponen utama yaitu PHP sebagai bahasa pemrograman, PhpMyAdmin sebagai database server dan Android sebagai aplikasi pembaca QR Code. Dari hasil uji coba dengan menggunakan Smartphone Sony Xperia 3 didukung dengan aplikasi Android yg telah dibangun. Dengan adanya aplikasi Absensi berbasis Web ini data dapat tersimpan ke database, siswa tidak perlu menunggu lama untuk absensi dan dapat meminimalisir kecurangan absensi.
\end{abstract}

Kata kunci : Absensi Siswa, Android, Aplikasi, QR Code, PHP

\begin{abstract}
Zunurain Aqila Zahra Vocational School is a secondary education institution founded by the Aqila Zahra Dumai Foundation. Every activity that requires information about students (students) will require attendance. The attendance process is still manual, namely by writing in books that require a long time and attendance fraud often occurs. With this problem, an application was made using the QR Code (Quick Response Code) and Web-based. The method used is through several stages such as data collection, identifying problems, system analysis, system design, system development, system testing, system implementation. This Web application is built using 3 main components, namely PHP as a programming language, PhpMyAdmin as a database server and Android as a $Q R$ Code reader application. From the results of trials using the Sony Xperia 3 Smartphone supported by Android applications that have been built. With this Web-based Attendance application data can be saved to the database, students do not have to wait long for attendance and can minimize attendance fraud.
\end{abstract}

Keywords: Android, Application, QR Code, Student Attendance, PHP

\section{PENDAHULUAN}

SMK Zunurain Aqila Zahra merupakan suatu lembaga pendidikan tingkat menengah yang didirikan oleh Yayasan Aqila Zahra Dumai, didirikan pada tanggal 01 Juli 2015, terletak di Jalan Pertanian Kelurahan Pelintung Kecamatan Medang Kampai. Pada awalnya SMKIT Zunurain Aqila Zahra belum memiliki gedung sekolah lebih kurang selama 5 (lima) bulan, dalam masa 5 (lima) bulan siswa-siswi melakukan proses belajar di gedung SDIT Aqila Zahra lantai 3 yang terletak di Jl. Arifin Ahmad KM.17 sampai gedung SMKIT ini berdiri. Pada saat ini proses absensi di SMKIT Zunurain Aqila Zahra dilakukan dengan proses konvensional dimana proses pengambilan daftar kehadiran siswa dilakukan secara manual 
I N F O R M A I I A

Jurnal Informatika, Manajemen dan Komputer, Vol. 11, No. 1 , MEl 2019

eISSN : 2580-3042

pISSN : 1979-0694

dengan menuliskan kehadiran siswa pada buku absensi siswa.

Absensi adalah sebuah kegiatan pengambilan data guna mengetahui jumlah kehadiran pada suatu acara. Setiap kegiatan yang membutuhkan informasi mengenai peserta tentu akan melakukan absensi, pada SMKIT Zunurain Aqila Zahra pengambilan daftar hadir dilakukan 2 (dua) sampai 4 (empat) kali dalam satu hari proses belajar, dengan perhitungan apabila pada satu jam mata pelajaran siswa/i tidak hadir atau tanpa keterangan (alfa) maka siswa siswi tersebut dianggap tidak hadir dalam 1 (satu) hari kegiatan belajar, begitu pula bila siswa siswi sakit maupun izin dalam pembelajaran yang sedang berlangsung. Berdasarkan observasi yang dilakukan di SMKIT Zunurain Aqila Zahra, proses absensi yang dilakukan oleh sekretaris kelas kurang efisien dan efektif dalam pelaksanaannya, data absensi yang ada mengalami kerusakan disebabkan oleh kondisi buku, faktor alam dan unsur ketidak sengajaan dalam memberikan rekapitulasi hasil absensi kepada Wali kelas. Ketidak sesuaian data absensi dapat merugikan siswa seringkali terdapat perbedaan absensi yang tertera pada rekap absen dengan data yang sebenarnya. Oleh karena itu maka dibuatlah sebuah sistem Absensi Siswa menggunakan $Q R$ Code dengan bahasa pemrograman PHP yang akan diterapkan di SMKIT Zunurain Aqila Zahra Medang Kampai, yang mana dalam hal ini pengertian $Q R$ Code, kependekan dari Qiuck Response Code, merupakan gambar dua dimensi yang memiliki kemampuan untuk menyimpan data. $Q R$ Code biasa digunakan untuk menyimpan data berupa teks, baik itu numerik, alfanumerik, maupun kode biner.

\section{a. Aplikasi}

Menurut (Juansyah Andi, 2015) Secara istilah pengertian aplikasi adalah suatu program yang siap untuk digunakan yang dibuat untuk melaksanankan suatu fungsi bagi pengguna jasa aplikasi serta penggunaan aplikasi lain yang dapat digunakan oleh suatu sasaran yang akan dituju. Menurut kamus computer eksekutif, aplikasi mempunyai arti yaitu pemecahan masalah yang menggunakan salah satu tehnik pemrosesan data aplikasi yang biasanya berpacu pada sebuah komputansi yang diinginkan atau diharapkan maupun pemrosesan data yang di harapkan. Pengertian aplikasi menurut Kamus Besar Bahasa Indonesia, "Aplikasi adalah penerapan dari rancang sistem untuk mengolah

data yang menggunakan aturan atau ketentuan bahasa pemrograman tertentu.

\section{b. Absensi}

Menurut (Setiawan \& Kurniawan, 2015) Absensi dapat dikatakan sebagai suatu pendataan kehadiran yang merupakan bagian dari aktifitas pelaporan yang ada dalam sebuah institusi. Absensi disusun dan diatur sehingga mudah untuk dicari dan dipergunakan ketika diperlukan oleh pihak yang berkepentingan. Secara umum jenis-jenis absensi menurut cara penggunaannya dapat dikelompokkan menjadi dua, yaitu: 1 Absensi Manual, yang merupakan cara penulisan kehadiran dengan cara menggunakan pena berupa tanda tangan. 2 Absensi non manual, yang merupakan cara penulisan kehadiran dengan menggunakan alat yang terkomputerisasi, bisa menggunakan kartu RIFD ataupun fingerprint.(Sugiarto, Linarta, \& Sofian, 2017)

\section{c. Sistem Absensi}

Sistem absensi yang merupakan sebuah sistem yang di gunakan untuk mencatat daftar kehadiran setiap anggota instansi tersebut. Sistem absensi mencatat identitas anggota instansi dan waktu keluar- masuk anggotanya.sistem absensi juga mempunyai kemapuan untuk memberikan laporan yang akurat. oleh karena itu,kebanyakan sekolah memanfaatkan daftar kehadiran siswa untuk menentukan kehadiran siswa tersebut selain itu,daftar kehadiran juga dapat memberikan informasi seberapa produktif sekolah itu dengan siswa yang di milikinya.(Rinjap, A, Sompie, \& Lantang, 2014)

\section{d. Data}

Data merupakan suatu kenyataan yang menggambarkan kejadian dan kesatuan nyata. Kejadian adalah sesuatu yang terjadi pada saat tertentu. Defenisi lain, data adalah fakta dari suatu pernyataan yang berasal dari kenyataan, dimana pernyataan itu adalah hasil pengukuran atau pengamatan. Data dapat berupa angka, huruf, simbol khusus, atau gabungan darinya. Data adalah bahan mentah bagi informasi, dirumuskan sebagai kelompok lambing tidak acak yang menunjukkan jumlah-jumlah, tindakan-tindakan, hal-hal, dan sebagainya. (Kaharu \& Sakina, 2015)

\section{e. PHP}

PHP (Hypertext Preprpcessor), merupakan bahasa pemrograman pada sisi server (Apache, iss, atau apapun) akan dieksekusi sebelum 
I N F ORM A I K A

Jurnal Informatika, Manajemen dan Komputer, Vol. 11, No. 1 , MEl 2019

eISSN : 2580-3042

pISSN : 1979-0694

perintah itu dikirim oleh halaman ke browser yang me-request-nya, contohnya adalah bagaimana memingkinkannya memasukkan tanggal sekarang pada sebuah halam web setiap kali tampilan tanggal dibutuhkan. Sesuai dengan fungsinya yang berjalan di sisi server maka PHP adalah bahasa pemrograman yang digunakan untuk membangun teknologi web application. (Herny \& Zuliarso, 2012)

\section{f. Android}

Menurut Nazruddin (Nazruddin 2012) Android adalah aplikasi sistem operasi untuk telepon seluler yang berbasis Linux. Android menyediakan platform terbuka bagi para pengembang untuk menciptakan aplikasi mereka sendiri untuk digunakan oleh bermacam piranti bergerak. (Sulihati \& Andriyani, 2016).

\section{g. QR Code}

Qr Code adalah image berupa matriks dua dimensi yang memiliki kemampuan untuk menyimpan data di dalamnya. $Q r$ Code merupakan evolusi dari kode batang (barcode). Barcode merupakan sebuah simbol penandaan objek nyata yang terbuat dari pola batangbatang berwarna hitam dan putih agar mudah untuk dikenali oleh computer sedangkan menurut (Sholeh \& Muharom, 2016) 'Qiuck Response Code sering disebut $Q R$ Code atau Kode QR adalah semacam simbol dua dimensi yang dikembangkan oleh Denso Wave yang merupakan anak prusahaan dari Toyota sebuah perusahaan Jepang pada tahun 1994. Tujuan dari $Q R$ Code ini adalah untuk menyampaikan informasi secara cepat dan juga mendapat tanggapan secara cepat. Pada awalnya $Q R$ Code digunakan untuk pelacakan bagian kendaraan yntuk manufacturing. Namun sekarang, telah digunkan untuk komersil yang ditunjukkan pada penggunaan telepon seluler. $Q R$ Code adalah perkembangan dari barcode atau kode batang yang hanya mampu menyimpan informasi lebih banyak, baik secara horizontal maupun vertikal. (Nugraha \& Munir, 2011)

Menurut (Denso, 2011), Qr Code dapat menghasilkan 40 versi yang berbeda dari versi 1 (21 x 21 modul) sampai versi $40(177 \times 177$ modul). Tingkatan Versi $\operatorname{Qr}$ Code 1 dan 2 berbeda 4 modul berlaku sampai dengan versi 40. Setiap versi memiliki konfigurasi atau jumlah modul yang berbeda. Modul ini mengacu pada titik hitam dan putih yang membentuk suatu $Q R$ Code. Setiap versi $Q R$ Code memiliki kapasitas maksimum data, jenis karakter dan tingkat koreksi kesalahan. Jika Jumlah data yang ditampung banyak maka

modul yang yang akan diperlukan dan menjadikan $Q r$ Code menjadi lebih besar dalam jurnal (Sholeh \& Muharom, 2016).

\section{h. Flowchart}

Menurut (Jogiyanto, 2005), 'bagan alir (flowchart) adalah bagan (chart) yang menunjukkan alir (flow) didalam program atau prosedur system secara logika'. Bagan alir digunakan terutama untuk alat bantu komunikasi dan untuk dokumentasi. Ada lima macam bagan alir Bagan alir system (systems flowchart), Bagan alir dokumen (document flowchart), Bagan alir skematik (schematic flowchart), Bagan alir program (program flowchart), Bagan alir proses (process flowchart).

\section{i. Contex Diagram}

Menurut Zefriyenni dan Santoso (2015), Context Diagram adalah gambarn umum tentang suatu sistem yang terdapat didalam suatu organisasi yang memperlihatkan batasan (boundary) sistem, adanya interaksi antara eksternal entity dengan suatu sistem. Context Diagram merupakan alat bantu yang digunakan dalam menganalisa sistem yang akan dikembangkan. (Sukrianto \& Oktariana, 2017)

\section{METODOLOGI PENELITIAN}

Adapun metodologi yang digunakan pada penelitian ini :

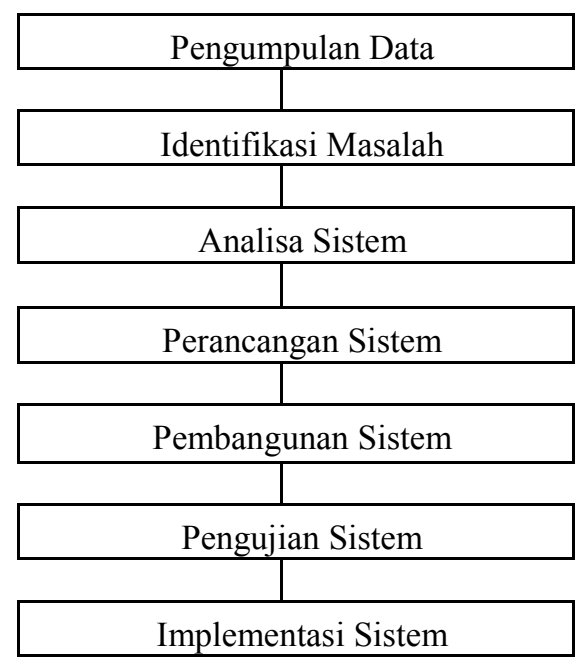

Gambar 1. Kerangka Kerja

Berikut ini penjelasan dari gambar Kerangka Kerja diatas:

1. Teknik Pengumpulan Data 
I N F O R M A I I A

Jurnal Informatika, Manajemen dan Komputer, Vol. 11, No. 1 , MEI 2019

eISSN : 2580-3042

pISSN : 1979-0694

Tahap pertama yang dilakukan adalah pengumpulan data dengan teknik wawancara dan observasi.

a. Teknik wawancara digunakan dalam pengumpulan data untuk mendapatkan jawaban pertanyaan dari pihak SMKIT Zunurain Aqila Zahra, pengumpulan data yang didapat dari hasil wawancara dijadikan acuan sebagai bahan untuk menyelesaikan penelitian ini. Wawancara dilakukan dengan Kepala Sekolah dan Tata Usaha SMKIT Zunurain Aqila Zahra, tujuan wawancara dilakukan untuk mengetahui sistem absensi yang dilakukan pada sekolah tersebut.

b. Observasi untuk pengumpulan data dengan mengadakan pengamatan terhadap sistem kerja dari permasalahan yang diteliti. Data yang dimaksud adalah data siswa, data guru, dan data mata pelajaran.

2. Identifikasi Masalah

Tahapan selanjutnya untuk membuat Aplikasi Absensi Siswa Menggunakan $Q R$ Code adalah dengan mengetahui persoalan atau masalah-masalah apa yang sedang dihadapi sebelum pembuatan aplikasi untuk dapat diatasi dengan melakukan penelitian ini.

3. Analisa Sistem

Untuk membuat sebuah sistem baru dibutuhkan analisa terhadap sistem yang akan di rancang dan dibuat, agar sistem yang akan dihasilkan nantinya sesuai dengan tujuan dan hasil yang diharapkan. Data yang dikumpulkan seanjutnya dilakukan analisa untuk membangun sistem absensi siswa dengan menggunakan $Q R$ Code dengan bahasa pemrograman PHP.

4. Perancangan Sistem

Merancang sistem yang dibutuhkan dalam pembuatan Aplikasi Absensi Siswa Menggunakan $Q R$ Code dengan Bahasa Pemrograman PHP di SMKIT Zunurain Aqila Zahra yaitu perancangan input, output yang sesuai dan memenuhi kebutuhan sistem.

5. Pembangunan Sistem

Pada tahap ini dilakukan pembangunan sistem Aplikasi Absensi Siswa Menggunakan $Q R$ Code dengan Bahasa Pemrograman PHP di SMKIT Zunurain Aqila Zahra, pembuatan $Q R$ Code dengan format .jpg di luar konteks aplikasi yang dibangun dimana pembuatan $Q R$ Code

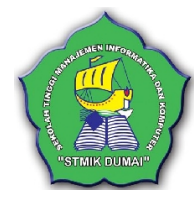

dilakukan pada Google Sheet, aplikasi PHP yang dibagun berfungsi sebagai media untuk mengintegrasikan hasil scan gambar $Q R$ Code yang berisi nomor induk siswa ke data base yang dibangun dan aplikasi android sebagai aplikasi pendukung pembacaan $Q R$ Code yang nanti akan mengmbil informasi real time.

6. Uji Coba Sistem.

Tahapan selanjutnya adalah pengujian program Aplikasi Absensi Siswa menggunakan $Q R$ Code dengan bahasa pemrograman PHP yang telah dirancang dengan menjalankan program yang telah selesai dibangun untuk mengetahui apakah aplikasi dapat digunakan

7. Implementasi

Pada tahap ini dilakukan pengimplementasian sistem Absensi Siswa Menggunakan $Q R$ Code dengan Bahasa Pemrograman PHP di SMKIT Zunurain Aqila Zahra untuk mendapatkan hasil yang sesuai dengan yang diharapkan.

3. HASIL DAN PEMBAHASAN

a. Aliran Sitem Informasi Yang Sedang Berjalan.

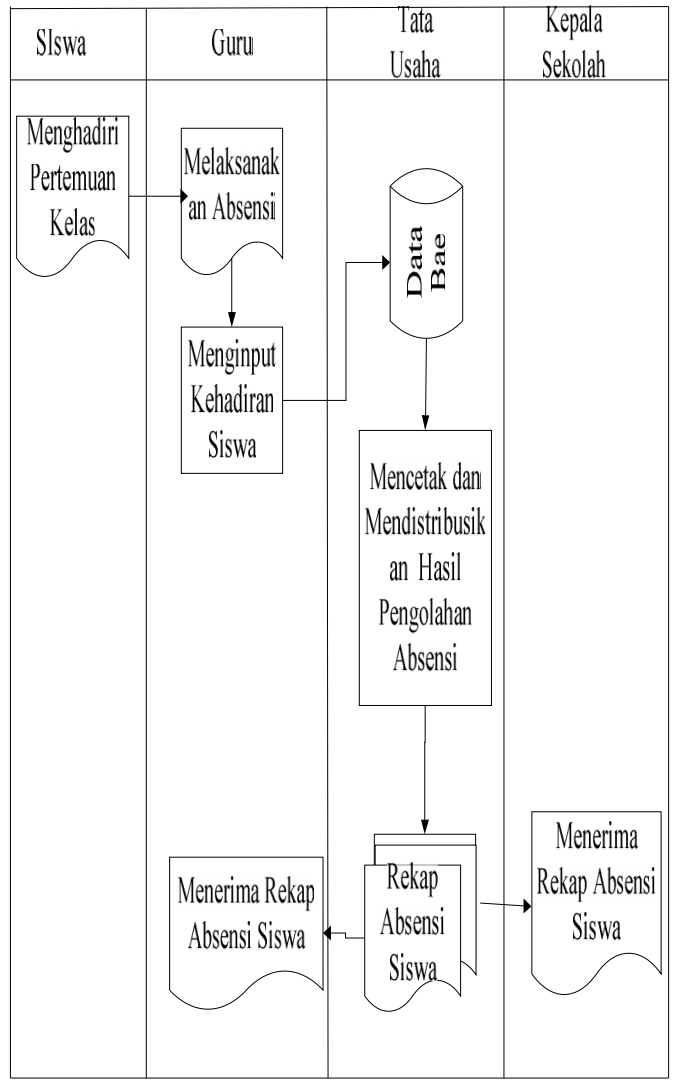

Gambar 2 Aliran Sistem Informasi 
I N F ORM A I K A

Jurnal Informatika, Manajemen dan Komputer, Vol. 11, No. 1 , MEl 2019

eISSN : 2580-3042

pISSN : 1979-0694

\section{b. Context Diagram}

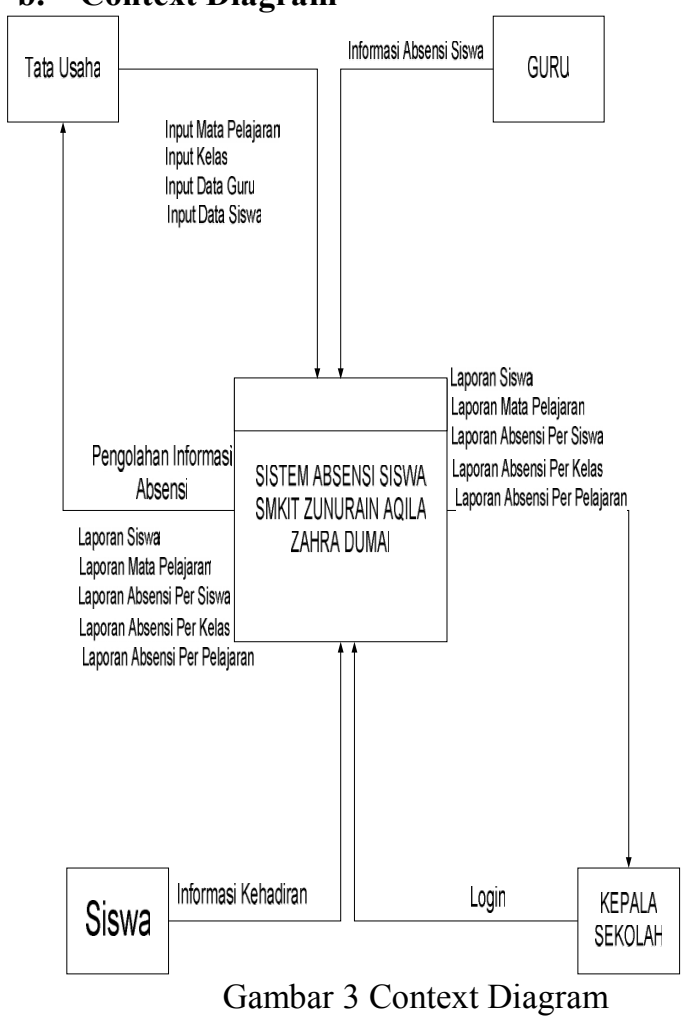

\section{c. Data Flow Diagram}

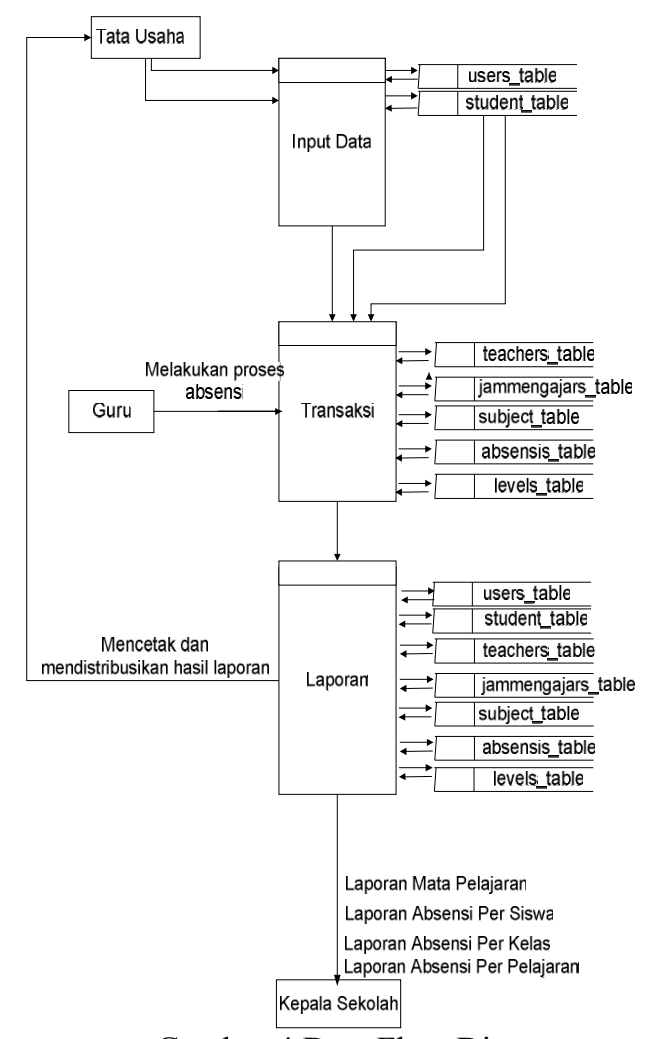

d. Tampilan Program

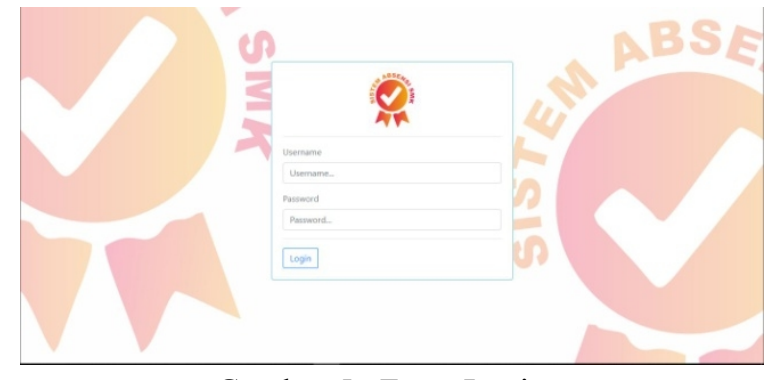

Gambar 5. Form Login

Untuk membuka sistem masukkan username dan password yang sudah ada di database. Sistem ini memiliki 2 hak akses untuk admin, dan guru. Admin bertanggung jawab atas sistem dalam mengakses dan melakukan input nama guru, input nama siswa, input mata pelajaran, input kelas, intput jurusan serta melakukan pengolah laporan absensi. Guru hanya bertugas melakukan proses absensi dengan melakukan scan QR Code siswa melalui aplikasi AbsenZaz.apk yang telah terinstal pada SmartPhone. Pada halaman login, jika username dan password benar maka sistem

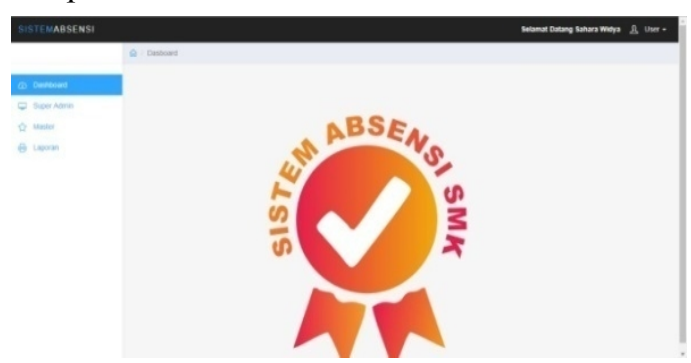

Gambar 6. Form Menu Utama Admin

Pada menu utama Admin terdapat menumenu yang memiliki fungsi masing-masing, yaitu menu Admin, Master dan menu laporan. Di dalam menu Admin terdapat sub menu user, techers, levels dan student, pada Admin terdapat sub menu subject dan absensi pada menu laporan terdapat sub menu siswa, mata pelajaran, absensi persiswa, absensi perkelas, absensi persemester dan absensi perhari.

\section{Dashboar/Menu Utama Guru}

Pada menu utama guru hanya menampilkan dashboard dan menu absensi dimna fungsi dari menu absensi sebagi menu tampilan hasil dari proses scan QR Code yang telah dilakukan

Gambar 4 Data Flow Diagram 


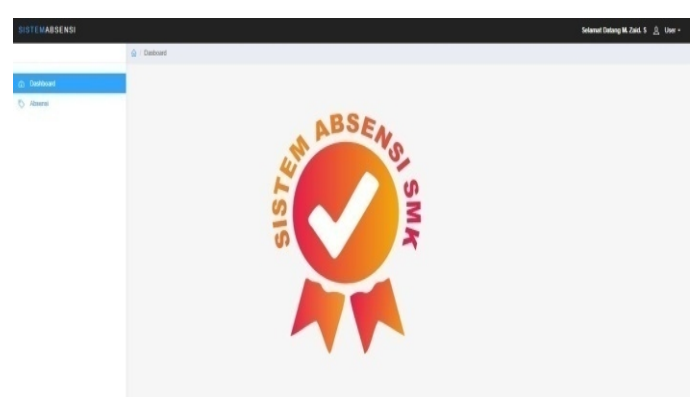

Gambar 7. Form Menu Utama Guru

Form Data User

Pada halaman Admin pilih sub menu bagian users. Pada form user terdapat tombol simpan. Pada aksi terdapat tombol ubah untuk mengubah data dan tombol hapus untuk menghapus data. User bertugas melakukan input data guru maupun user lainnya.

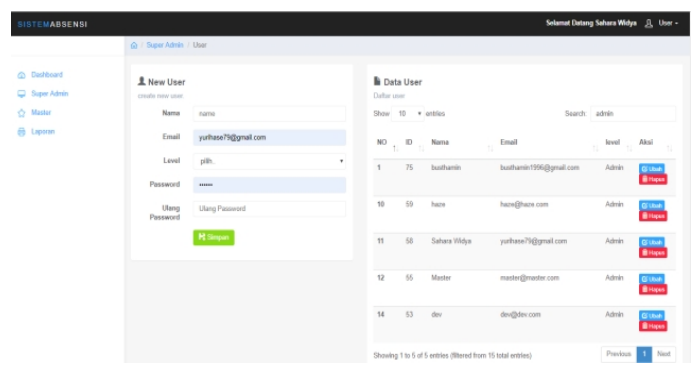

Gambar 8. Form Data User

Form Data Teachers

Pada halaman Admin pilih sub menu bagian teacher. Pada form guru terdapat tombol submit. Pada aksi terdapat tombol ubah untuk mengubah data dan tombol hapus untuk menghapus data.

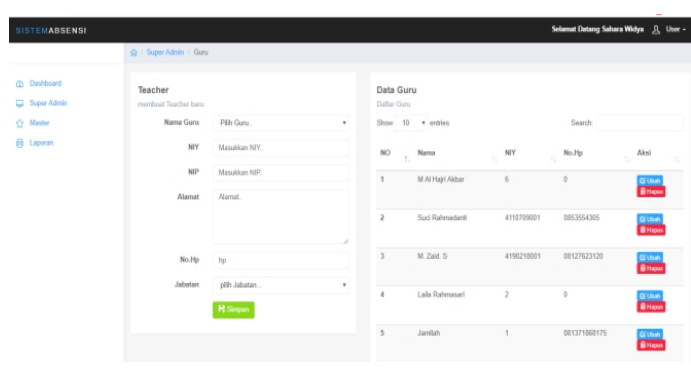

Gambar 11 Form Data Teachers

Form Data Levels

Pada halaman Admin pilih sub menu bagian levels. Pada form kelas terdapat tombol submit, tombol kelas berfungsi untuk menambah kelas dan tombol jurusan untuk menambah jurusan. Pada aksi terdapat tombol hapus untuk menghapus data.

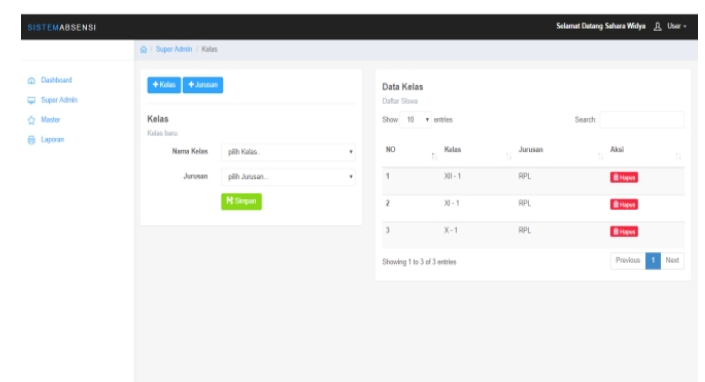

Gambar 10. Form Data Levels

Form Data Students

Pada halaman Admin pilih sub menu bagian Student. Pada form siswa terdapat tombol simpan. Pada aksi terdapat tombol ubah untuk mengubah data dan tombol hapus untuk menghapus data.

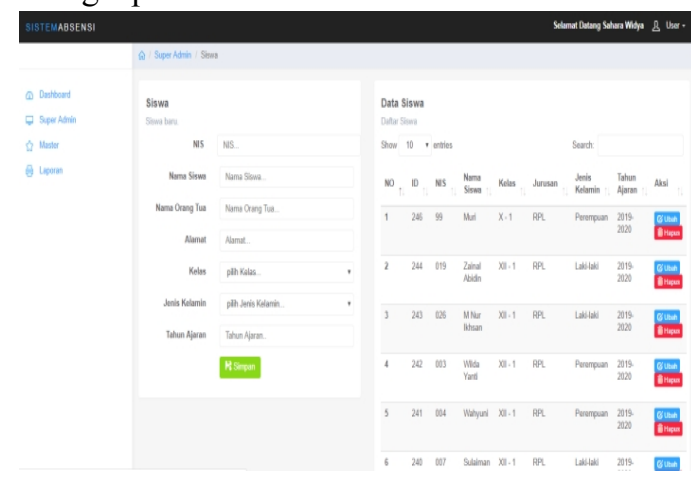

Gambar 11. Form Data Student

Form Data Subject

Pada halaman master pilih submenu bagian subject. Pada form jadwal pelajaran terdapat tombol submit. Pada aksi terdapat tombol ubah untuk mengubah data, tombol jam untuk mengatur jadwal lihat pada gambar 4.9 dan tombol hapus untuk menghapus data.

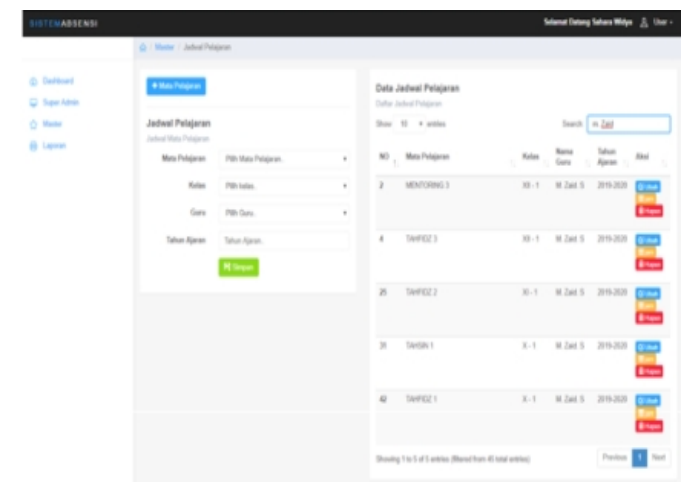

Gambar 12. Form Data Subject 
I N F ORM A I K A

Jurnal Informatika, Manajemen dan Komputer, Vol. 11, No. 1 , MEl 2019

eISSN : 2580-3042

pISSN : 1979-0694

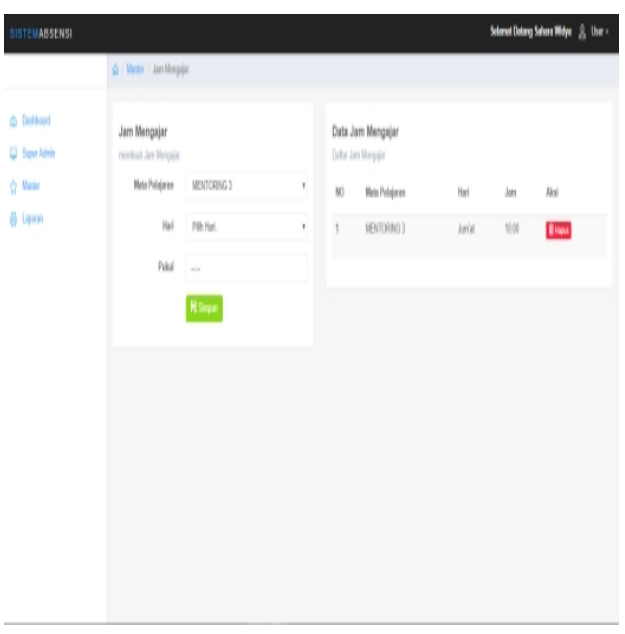

Gambar 13. Form Jam Mengajar

Form Absensi

Pada halaman master pilih submenu bagian absensi. Form absensi berfungsi sebagai tampilan dari hasil proses absensi melalui scan QR Code dan juga berfungsi sebagai input manual kehadiran siswa bila lupa membawa kartu siswa atau siswa dengan keterangan sakit, izin dan alfa. Pada form absensi terdapat tombol lembaran absen yg berfungsi untuk menambah lembar baru dalam 1 (satu) minggu pembelajaran, dan simpan untuk menyimpan data kehadiran siswa yang dilakukan secara manual.

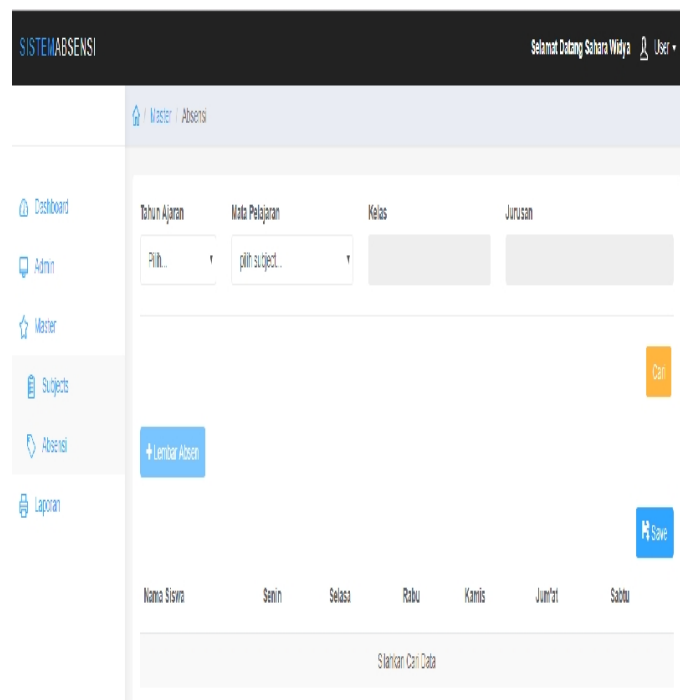

Gambar 14. Form Absensi

Form siswa

Pada halaman laporan pilih submenu bagian siswa. Maka akan tampil laporan nama siswa berdasarkan kelas dan jurusan.

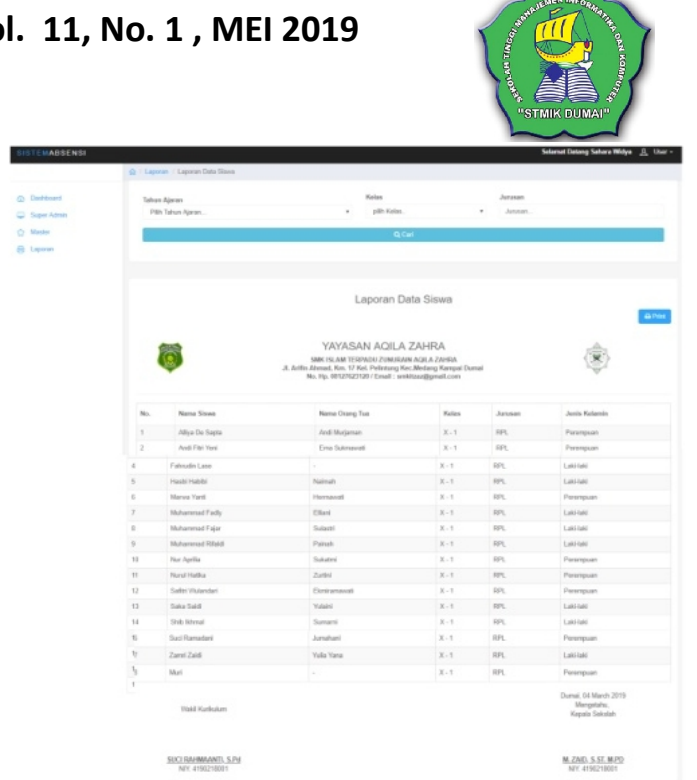

Gambar 15. Form Siswa

Form Mata Pelajaran

Pada halaman laporan pilih submenu bagian mata pelajran. Maka akan tampil laporan jadwal mata pelajaran berdasarkan kelas dan jurusan.

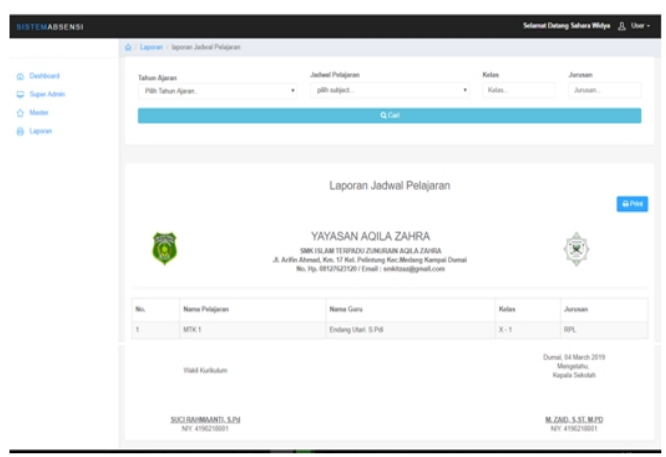

Gambar 16. Form Mata Pelajaran

Form Laporan Absensi Per Siswa

Pada halaman laporan pilih submenu bagian Absensi Per Siswa. Maka akan tampil laporan absensi persiswa sesuai dengan nama siswa dan tahun ajaran.

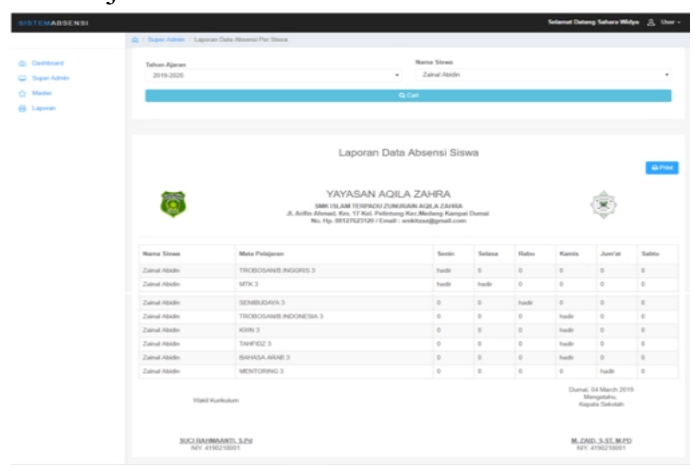

Gambar 17. Form Laporan Absensi Per Siswa 
I N F ORM A I K A

Jurnal Informatika, Manajemen dan Komputer, Vol. 11, No. 1 , MEl 2019

eISSN : 2580-3042

pISSN : 1979-0694

Form Laporan Absensi Per Kelas

Pada halaman laporan pilih submenu bagian Absensi Per Kelas. Maka akan tampil laporan absensi per kelas sesuai dengan tahun ajaran dan kelas.

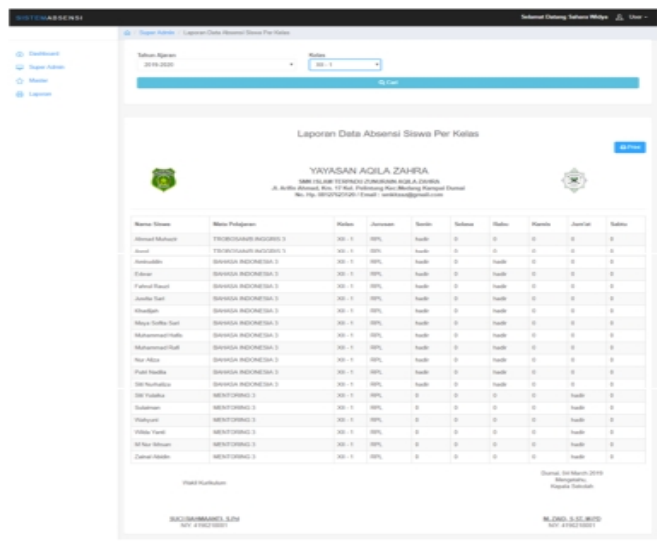

Gambar 18. Form Laporan Absensi Per Kelas

Form Laporan Absensi Per Pelajaran

Pada halaman laporan pilih submenu bagian Absensi Per Pelajaran. Maka akan tampil laporan absensi per pelajaran sesuai dengan tahun ajaran, mata pelajaran, jurusan dan kelas.

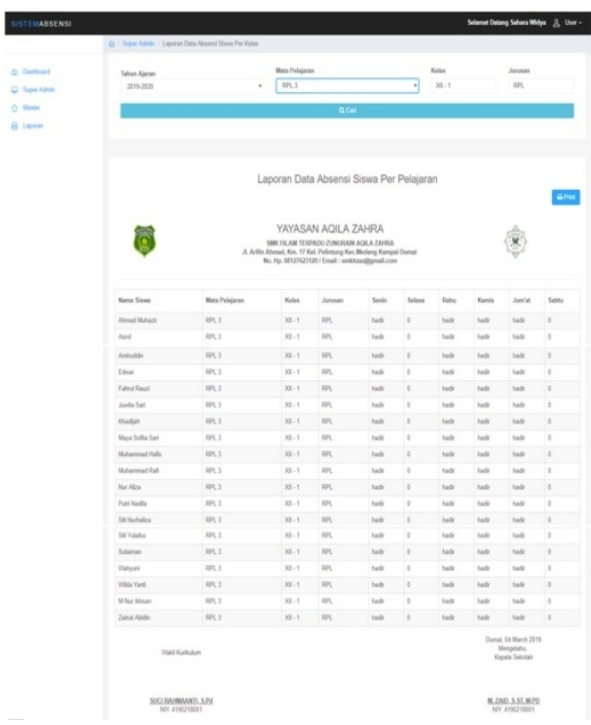

Gambar 19. Form Laporan Absensi Per Pelajaran

Form Laporan Absensi Per Semester

Pada halaman laporan pilih submenu bagian Absensi Per Semester. Maka akan tampil laporan absensi per semester sesuai dengan tahun ajaran, mata pelajaran, jurusan dan kelas.

\section{Aplikasi Absensi Zaz}

Aplikasi absensizaz.apk terlebih dahulu di instaldi SmartPhone masing-masing guru. setelah instalasi selesai akan tampil menu login.

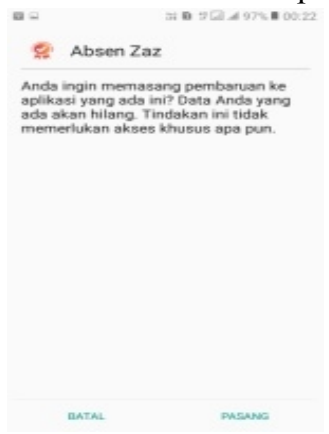

Gambar 20. Instal Apk

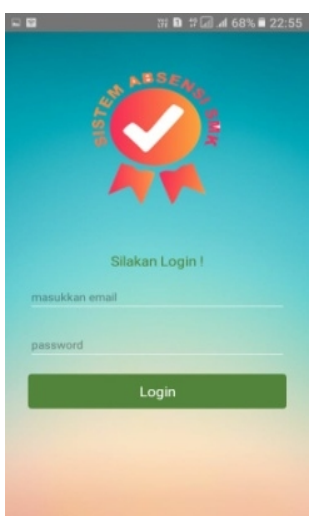

Gambar 21. Form Login

Login dilakukan dengan mengisi alamat email dan password dengan benar. Jika login berhasil maka akan masuk ke halaman baru yaitu menu pilih jadwal.

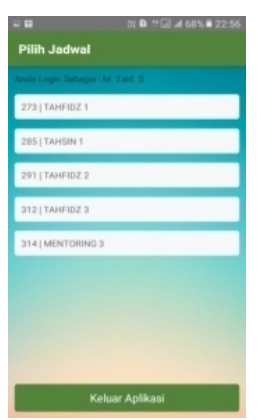

Gambar 22. Tampilan Mata Pelajaran

Tampilan Pilih Jadwal akan menampilkan seluruh materi pelajaran yang di tugaskan pada guru bidang studi yang bersangkutan, dalam hal ini guru memilih salah satu matpelajaran yang akan dilakukan untuk selanjutnya dapat melakukan proses scan QR Code guna melakukan proses absensi siswa. Selanjutnya 
I N F O R M A I I A

Jurnal Informatika, Manajemen dan Komputer, Vol. 11, No. 1 , MEl 2019

eISSN : 2580-3042

pISSN : 1979-0694

akan tampil menu pilihan scan absen lakukan proses scan dengan mengarahkan camera pada QR Code siswa.

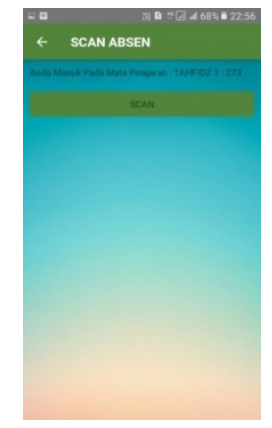

Gambar 23. Tampilan Scan Absen

Arahkan camera SmartPhone pada gambar QR Code yang ada, pastikan gambar tertangkap dengan baik oleh kamera.

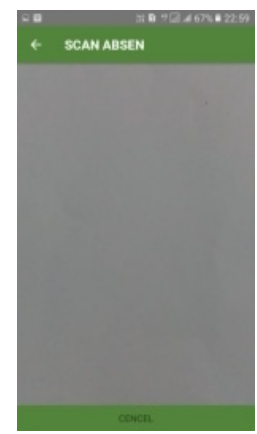

Gambar 24. Tampilan Scan QR Code

\section{KESIMPULAN}

Berdasarkan hasil penelitian maka dapat diambil kesimpulan antara lain:

1. Data absensi siswa sudah dapat tersimpan dalam database sehingga mempermudah dalam membuat laporan Daftar kehadiran siswa.

2. Mengintegrasikan informasi dari proses absensi kedalam sistem yang akan dibangun dan merancang suatu sistem agar lebih cepat, mudah dan tepat dalam proses absensi siswa.

3. Kecurangan dalam proses anbsensi bisa di minimalisir karena tidak menggunakan absensi secara tertulis.

\section{REFERENSI}

Herny, F., \& Zuliarso, E. (2012). Rancang Bangun Sistem Perpustakaan Untuk Jurnal Elektronik. Jurnal Teknologi Informasi DINAMIK, 17(2), 124-132.

Jogiyanto. (2005). Analisis Dan Desain (3rd

ed.). Yogyakarta: C.V ANDI OFFSET (Penerbit ANDI).

Juansyah Andi. (2015). Pembangunan Aplikasi Child Tracker Berbasis Assisted - Global Positioning System (a-Gps) Dengan Platform Android. Jurnal Ilmiah Komputer Dan Informatika (KOMPUTA), 1(1), 1-8. Retrieved from elib.unikom.ac.id/download.php?id=3003 75

Kaharu, S., \& Sakina, O. (2015). Perancangan Sistem Informasi Pengolahan Data Akademik Pada Tk Al-Hidayah Lolu.

Nugraha, M. P., \& Munir, R. (2011). Pengembangan Aplikasi Qr Code Generator Dan Qr Code Reader Di Data Berbentuk Image. Konferensi Nasional Informatika - KNIF 2011, 148-155.

Rinjap, A. S., A, S. R. U., Sompie, \& Lantang, O. (2014). Aplikasi Absensi Siswa Menggunakan Sidik Jari Di Sekolah Menengah Atas Negeri 9 Manado. EJournal, 1-5.

Sholeh, M. L., \& Muharom, L. A. (2016). Smart Presentasi Menggunakan Qr-Code. Universitas Muhammadiyah Jember, 13(2), 31-44.

Sugiarto, M. I., Linarta, A., \& Sofian, A. (2017). Aplikasi Layanan Informasi Absen Dan Nilai Berbasis Sms Getway Menggunakan Php Pada Smk Taruna Persada Dumai, 9(2), 60-69.

Sukrianto, D., \& Oktariana, D. (2017). Pemanfaatan Teknologi Barcode Pada Sistem Informasi Perpustakaan Di Smk Muhammadiyah 3 Pekanbaru, 1(2), 136143.

Sulihati, \& Andriyani. (2016). Aplikasi Akademik Online Berbasis Mobile Android. Jurnal Sains Dan Teknologi Utama, Volume XI, Nomor 1, April 2016, XI(152). 